\title{
Integrated anti-remodeling and anabolic therapy for the osteoporosis of Hajdu-Cheney syndrome
}

\author{
F. E. McKiernan
}

Published online: 31 January 2007

(C) International Osteoporosis Foundation and National Osteoporosis Foundation 2007

Due to an error in typesetting, the last sentence of the abstract referred to "activated osteoporosis", instead of the correct "activated osteolysis". The abstract is reproduced here in full.

The online version of the original article can be found at: http://dx.doi. org/10.1007/s00198-006-0221-z.

F. E. McKiernan $(\bowtie)$

Center for Bone Diseases, Marshfield Clinic,

1000 N. Oak Avenue,

Marshfield, WI 54449, USA

e-mail: mckiernan.fergus@marshfieldclinic.org

\begin{abstract}
Hajdu-Cheney syndrome (MIM 102500) is a rare skeletal dysplasia marked by severe generalized osteoporosis and focal bone loss (acro-osteolysis). Osteoporosis treatment outcome has been reported only once previously. Reported herein is the biochemical and densitometric response to integrated anti-remodeling and anabolic therapy in a woman with Hajdu-Cheney syndrome. Results suggest dissociation of bone formation from bone resorption resulting in dramatic increases in bone mineral density without clinical evidence of activated osteolysis.
\end{abstract}

